\title{
CITRA DESTINASI DAN STRATEGI PEMASARAN DESTINASI WISATA
}

\author{
Budi \\ Program Studi Manajemen, Universitas Bunda Mulia
}

\begin{abstract}
Destination image is an important factor in tourism marketing. Destination image consists of cognitive, affective and conative dimensions. Understanding formation process of destinations image will help the tourism marketers to build or improve destination image that will facilitate loyal visitors to re-visit or recommend to others. This is quantitative research. Instrument was developed by adopting previous studies but still taking into account its relevance. Questionnaires were distributed through the internet network. Subjects of the study who are not residents of Jakarta, and were at least 17 years old. Determination of sample was using random sampling method. Validity Test, Reliability Test, Signification Test, Determinant Test, and Mediation Test were performed. Results show that cognitive affect affective, cognitive affect conative, cognitive together with affective affect conative. Implication of these findings for tourism marketers is destination image constructed from cognitive into affective then into connative. Then tourism marketers should not only focus to build induces cognitive image but organic image as well.Tourism marketers should aware on general information exists in public communication channels and social media regarding on tourist destination that they 'sell'. These information will form cognitive destination image, then affect feeling and ultimately affect actions that will be done by tourists on that tourism destination.
\end{abstract}

Keywords: destination image, induced, organic, cognitive, affective, conative

\begin{abstract}
ABSTRAK
Citra destinasi merupakan faktor penting dalam pemasaran pariwisata. Citra destinasi terdiri dari dimensi kognitif, afektif dan konatif. Memahami proses pembentukan citra destinasi akan membantu pemasar pariwisata untuk membangun atau meningkatkan citra destinasi yang akan memfasilitasi pengunjung setia untuk mengunjungi kembali atau merekomendasikan kepada orang lain. Penelitian ini adalah penelitian kuantitatif. Instrumen dikembangkan dengan mengadopsi studi sebelumnya tetapi tetap mempertimbangkan relevansinya. Kuesioner dibagikan melalui jaringan internet. Subyek penelitian adalah mereka yang bukan penduduk Jakarta, dan berusia minimal 17 tahun. Penentuan sampel menggunakan metode random sampling. Uji yang dilakukan adalah Uji Validitas, Uji Reliabilitas, Tes Signifikasi, Uji Determinan, dan Uji Mediasi. Hasil menunjukkan bahwa kognitif mempengaruhi afektif, kognitif mempengaruhi konatif, kognitif bersama afektif mempengaruhi konatif. Implikasi dari temuan ini bagi pemasar pariwisata adalah citra destinasi yang dibangun dari kognitif menjadi afektif kemudian menjadi konatif. Maka pemasar pariwisata sebaiknya tidak hanya fokus untuk membangun induced destination image tetapi juga organic destination image. Pemasar wisata harus sadar akan informasi umum yang beredar di saluran komunikasi publik dan media sosial mengenai destinasi wisata yang mereka jual. Informasi ini akan membentuk citra tujuan kognitif, kemudian mempengaruhi perasaan dan pada akhirnya mempengaruhi tindakan yang akan dilakukan oleh wisatawan pada tujuan pariwisata tersebut.
\end{abstract}

Kata kunci: citra destinasi, induced, organik, kognitif, afektif, konatif 


\section{PENDAHULUAN}

Sektor pariwisata saat ini telah menjadi salah satu industri yang berkontribusi penting bagi ekonomi suatu negara. Data World Travel \& Tourism Council (WTTC) menunjukkan bahwa pada tahun 2015 industri travel \& tourism dunia diperkirakan menyerap sebanyak 107,519 juta pekerja atau setara dengan 3,6\% tenaga kerja dunia. Jika memperhitungkan industri yang terkait dengan industri travel \& tourism maka jumlah pekerja yang diserap adalah sebanyak 283,983 juta pekerja atau setara dengan 9,5\% total pekerja dunia. Dilihat dari kontribusi GDP, industri travel \& tourism menyumbangkan USD 2.451 triliun atau setara dengan 3,7\% GDP dunia. Dan jika memasukkan industri yang terkait industri travel \& tourism maka nilai kontribusinya mencapai USD 7,86 triliun atau setara dengan 9.9\% GDP dunia (World Travel \& Tourism Council, 2015b).

Indonesia sendiri mengakui pentingnya kontribusi sektor pariwisata bagi perekonomian nasional. Kunjungan wisatawan mancanegara ke Indonesia tahun 2016 mencapai 12.023.971 wisatawan atau tumbuh $15,54 \%$ dibandingkan tahun 2015 (http://industri.bisnis.com/read/20170218/1 2/629896/kunjungan-wisman-2016-lebihitarget-12-juta-orang).

Indonesia menargetkan kunjungan wisatawan mancanegara dapat mencapai 20 juta wisatawan pada tahun 2020 (http://www.koran-jakarta.com/pariwisatakunci-penggerak-ekonomi-global/).

Kontribusi sektor pariwisata terhadap GDP Nasional Indonesia tahun 2015 mencapai Rp. 1.107 triliun atau setara dengan 9.9\% GDP Indonesia (World Travel \& Tourism Council,
2016). Industri pariwisata indonesia menyerap sebanyak 3,404 juta pekerja atau setara dengan 2,9\% angkatan kerja nasional. Dan jika mengikut sertakan industri yang terkait dengan pariwisata maka angkatan kerja yang terserap adalah sebanyak 10,140 juta pekerja atau setara dengan $8,5 \%$ total pekerja nasional.

Pengembangan sektor pariwisata dapat dilakukan dengan memaksimalkan strategi pemasaran destinasi wisata. Keberhasilan pemasaran suatu destinasi wisata ditentukan oleh seberapa menariknya suatu destinasi wisata dibandingkan daya tarik destinasi wisata lainnya (Dwyer et al., 2000 dalam AlKwifi 2015). Citra destinasi akan menjadi acuan awal dalam menentukan seberapa menariknya suatu destinasi wisata, dan akan mempengaruhi keputusan tentang destinasi wisata yang akan dikunjungi (Al-Kwifi, 2015). Citra destinasi mempengaruhi pembuatan keputusan tujuan wisata (AlKwifi, 2015), memiliki pengaruh positif persepsi nilai (Allameh et al , 2015; Chen and Tsai, 2007), memiliki pengaruh positif terhadap persepsi dan kepuasan (Allameh et al., 2015), memiliki pengaruh positif terhadap keinginan untuk melakukan kunjungan ulang (Allameh et al., 2015; Assaker et al., 2011; Greaves dan Skinner, 2010), memiliki pengaruh positif terhadap loyalitas turis (Akroush et al., 2016), dan memiliki pengaruh positif terhadap behavioral intentions (Chen and Tsai, 2007). Pemahaman akan pembentukan citra destinasi akan membantu pelaku pemasar wisata untuk membangun atau meningkatkan citra destinasi yang memfasilitasi pengunjung setia untuk berkunjung ulang atau merekomendasikan kepada orang lain (Chen \& Tsai, 2007). 
Tabel 1. Kontribusi Industri Pariwisata Bagi Perekonomian Indonesia dan Dunia

\begin{tabular}{|c|c|c|}
\hline & Indonesia & Dunia \\
\hline \multicolumn{3}{|l|}{ Kontribusi Industri Pariwisata Secara Langsung } \\
\hline \multicolumn{3}{|l|}{ Terhadap GDP } \\
\hline \multicolumn{3}{|l|}{ Tahun 2014} \\
\hline - Jumlah & Rp 325,467 triliun & USD 2,36 triliun \\
\hline - $\quad$ \% GDP Nasional/Dunia & $3,2 \%$ & $3,1 \%$ \\
\hline \multicolumn{3}{|l|}{ Tahun 2015} \\
\hline - Jumlah & Rp 345,102 triliun & USD 2,45 triliun \\
\hline - $\quad \%$ GDP Nasional/Dunia & $3,2 \%$ & $3,1 \%$ \\
\hline - $\quad$ Kenaikan GDP 2014-2015 & $6 \%$ & $3,7 \%$ \\
\hline \multicolumn{3}{|l|}{ Terhadap Penyerapan Tenaga Kerja } \\
\hline \multicolumn{3}{|l|}{ Tahun 2014} \\
\hline - Jumlah & 3,326 juta & 105,408 juta \\
\hline - $\quad \%$ Tenaga Kerja Nasional/Dunia & $2,9 \%$ & $3,6 \%$ \\
\hline \multicolumn{3}{|l|}{ Tahun 2015} \\
\hline - Jumlah & 3,404 juta & 107,519 juta \\
\hline - $\quad \%$ Tenaga Kerja Nasional/Dunia & $2,9 \%$ & $3,6 \%$ \\
\hline - $\quad$ Kenaikan Tenaga Kerja 2014-2015 & $2,3 \%$ & $2 \%$ \\
\hline \multicolumn{3}{|l|}{ Kontribusi Industri Pariwisata dan Industri Terkait } \\
\hline \multicolumn{3}{|l|}{ Terhadap GDP } \\
\hline \multicolumn{3}{|l|}{2014} \\
\hline - Jumlah & Rp 946,087 triliun & USD 7,58 triliun \\
\hline - $\quad$ \% GDP Nasional/Dunia & $9,3 \%$ & $9,8 \%$ \\
\hline \multicolumn{3}{|l|}{2015} \\
\hline - Jumlah & Rp 1.012,77triliun & USD 7,863 triliun \\
\hline - $\quad \%$ GDP Nasional/Dunia & $9,5 \%$ & $9,9 \%$ \\
\hline - $\quad$ Kenaikan GDP 2014-2015 & $7 \%$ & $3.7 \%$ \\
\hline \multicolumn{3}{|l|}{ Terhadap Penyerapan Tenaga Kerja } \\
\hline \multicolumn{3}{|l|}{2014} \\
\hline - Jumlah & 9,814 juta & 276,845 juta \\
\hline - $\quad \%$ Tenaga Kerja Nasional/Dunia & $8,4 \%$ & $9,4 \%$ \\
\hline \multicolumn{3}{|l|}{2015} \\
\hline - Jumlah & 10,140 juta & 283,983 juta \\
\hline - $\quad \%$ Tenaga Kerja Nasional/Dunia & $8,5 \%$ & $9,5 \%$ \\
\hline - Kenaikan Tenaga Kerja 2014-2015 & $3.3 \%$ & $2.6 \%$ \\
\hline
\end{tabular}

Sumber: World World Travel \& Tourism Council

\section{TINJAUAN PUSTAKA}

Citra destinasi adalah sekumpulan asosiasi yang dimiliki orang tentang daerah tujuan wisata (Kong et al., 2015). Citra destinasi adalah proses persepsi dan kognitif dari berbagai sumber informasi seperti brosur atau poster wisata, pendapat dari orang lain (keluarga/teman), ataupun media (koran, majalah, televisi, buku, film) (Lopes, 2011). Informasi sejarah, politik, ekonomi, dan sosial yang telah dimiliki seseorang tentang suatu tempat spesifik pada akhirnya akan membentuk suatu citra destinasi (Echtner and Richie, 1991). Citra destinasi adalah hasil proses persepsi dan kognitif yang dipengaruhi oleh sumber informasi, umur, tingkat pendidikan, motivasi dan budaya (Baloglu dan McCleary, 1999 dalam Lopez, 2011). 
Gambar 1. Pembentukan citra destinasi Menurut Baloglu dan McCleary (1999)

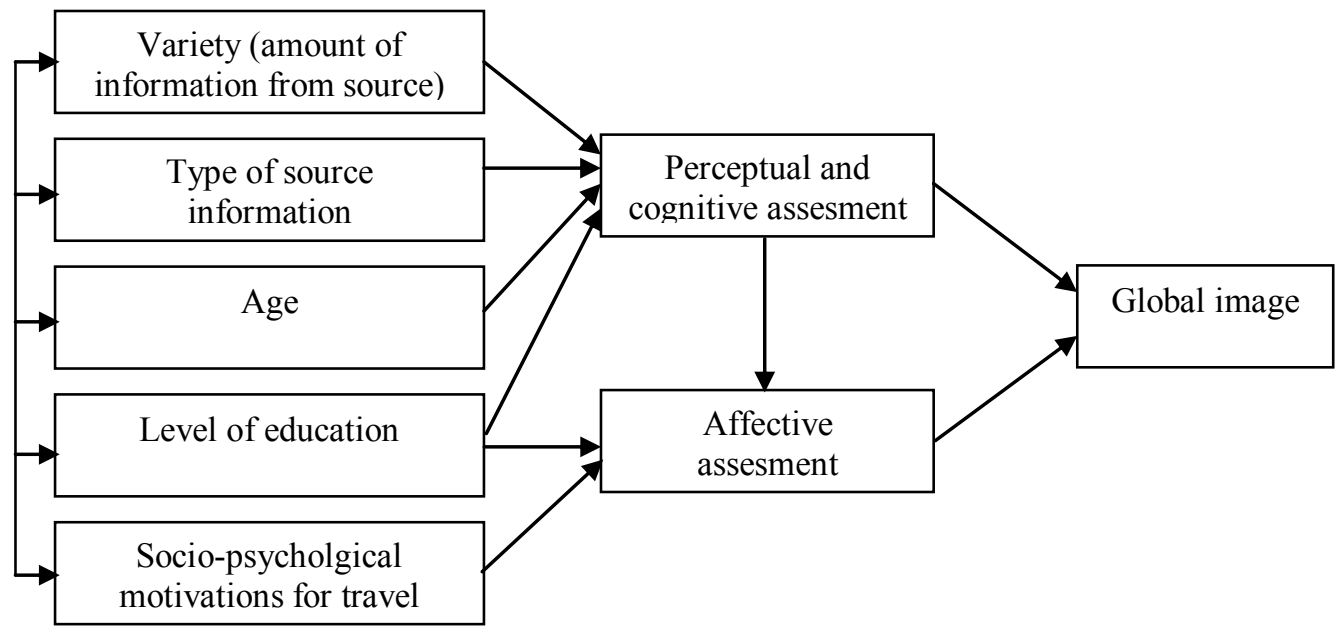

Sumber: Lopes, 2011

Stabler (1988 dalam Lopez, 2011) mengidentifikasi faktor-faktor yang lebih luas yaitu bahwa faktor psikologikal seperti motivasi dan nilai budaya juga turut mempengaruhi proses pembentukan citra destinasi yang dimiliki oleh seseorang.

\section{Gambar 2. Pembentukan citra destinasi Menurut Stabler (1988)}

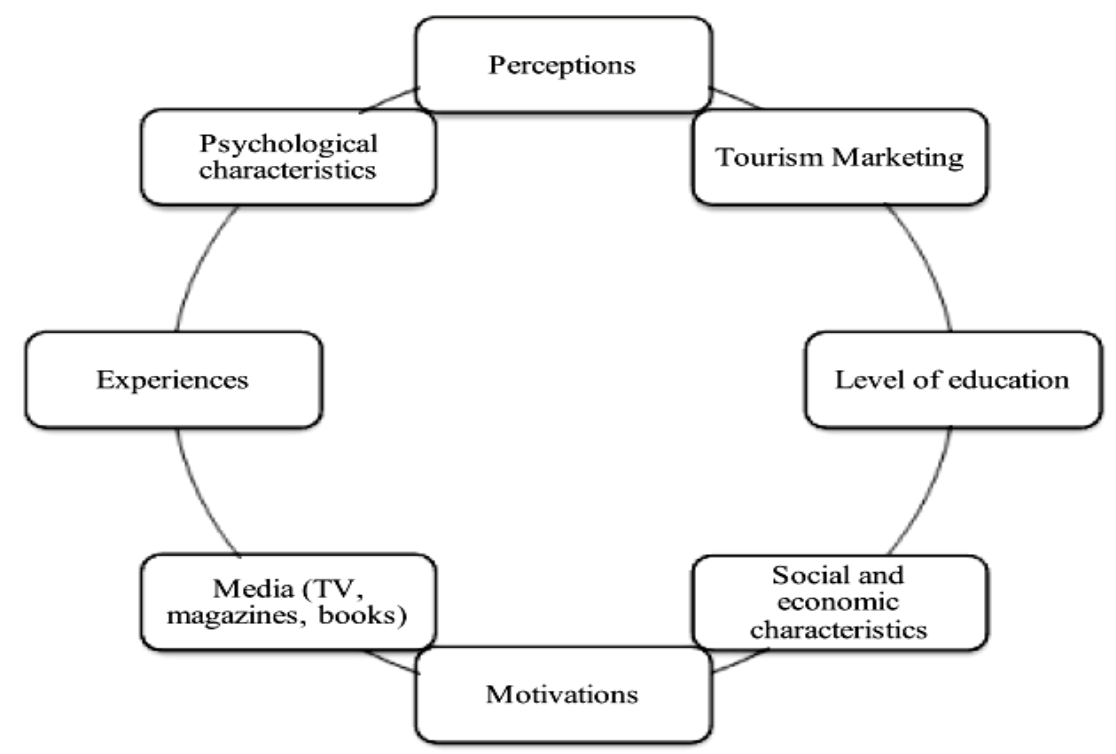

Sumber: Lopes, 2011

Gunn (1988, dalam Echtner and Ritchie 2003) menggunakan tujuh tahapan pengalaman perjalanan wisata untuk menjelaskan pembentukan citra destinasi. Tujuh tahapan tersebut adalah:

1) Akumulasi gambaran mental tentang pengalaman berlibur.

2) Modifikasi gambaran tersebut berdasarkan informasi yang didapatkan kemudian.
3) Keputusan untuk melakukan perjalanan liburan.

4) Berkunjung ke destinasi wisata.

5) Partisipasi di tempat wisata.

6) Kembali ke rumah.

7) Modifikasi gambaran tersebut berdasarkan pengalaman liburannya tersebut. 
dengan menggunakan model diatas pembentukan citra destinasi teridentifikasi terjadi pada tahap 1,2, dan 7 .

Citra destinasi yang terbentuk pada tahap-1 disebut dengan organic image. Gambaran (image) yang terbentuk pada tahap ini bersumber kepada informasi non-touristic, non-komersial seperti media massa (berita, majalah, buku, film), pendidikan/sekolah, dan pendapat dari keluarga atau teman. Seseorang dapat memiliki organic image terhadap suatu destinasi wisata meskipun orang tersebut tidak memiliki niat untuk melakukan perjalanan wisata kesana. Dalam konteks seseorang yang belum pernah berkunjung ke destinasi wisata maka citra destinasi yang mereka miliki akan dipengaruhi oleh faktor motivasi wisata, variabel demographic, dan informasi tentang destinasi wisata (Lopes, 2011).

Citra destinasi yang terbentuk pada tahap-2 disebut dengan induced image. Pada tahap ini image terbentuk melalui informasiinformasi pariwisata seperti brosur, iklan, buku perjalanan wisata. Informasi-informasi yang didapat pada tahap ini mungkin saja mengubah image yang telah dimiliki sebelumnya. Perbedaan utama antara organic image dan induced image terletak pada maksud atau motivasi melakukan perjalanan (Byon dan Zhang, 2010). Dengan kata lain, seseorang dapat memiliki organic image terhadap suatu destinasi wisata meskipun orang tersebut tidak memiliki niat untuk melakukan perjalanan wisata kesana; sedangkan induced image terbentuk karena memiliki niat untuk melakukan perjalanan wisata maka seseorang secara sengaja mencari informasi tentang destinasi wisata tersebut.

Kemudian pada tahap ke-7, pengalaman nyata setelah berkunjung ke destinasi wisata tersebut digunakan untuk mengubah citra destinasi yang dimiliki (Echtner and Ritchie, 2003). Jika pengalaman nyata yang dialami wisatawan sesuai atau melebihi harapan maka wisatawan akan merasa puas, menjadi loyal, melakukan kunjungan ulang, dan merekomendasikannya kepada orang lain (Akroush et al., 2016; Allameh et al., 2015; Al-Kwifi, 2015; Greaves dan Skinner, 2010; Chen and Tsai, 2007). Image yang terbentuk sebagai hasil pengalaman langsung seseorang ditempat wisata ini disebut juga dengan complex image (Byon dan Zhang, 2010).

Jadi, proses pembentukan citra destinasi adalah proses persepsi dan kognitif terhadap berbagai sumber informasi yang yang dipengaruhi oleh faktor-faktor internal dan eksternal seseorang. Berdasarkan sumbernya, citra destinasi ini dibedakan menjadi organic image (sumber informasi bersifat nontouristic, non-komersial) dan induced image (sumber informasi bersifat touristic, bersumber dari pemasar pariwisata). Kong et al. (2015) menyarankan agar pemasar wisata berfokus untuk mengubah induced image, karena hanya sedikit hal yang dapat dilakukan untuk mengubah organic image.

Citra destinasi yang terbentuk ini didefiniskan dalam berbagai definisi seperti yang dapat dilihat pada Tabel 1 berikut ini:

Tabel 2. Definisi-definisi Tentang Citra Destinasi

\begin{tabular}{ll}
\hline Pengarang & Definisi \\
\hline Lawson and & $\begin{array}{l}\text { Suatu ekspresi pengetahuan, kesan, prasangka, imajinasi, dan pemikiran- } \\
\text { pemikiran emosional dari seseorang terhadap suatu tempat spesifik. }\end{array}$ \\
Crompton (1979) & $\begin{array}{l}\text { Penjumlahan (sum) keyakinan, gagasan, dan kesan yang dimiliki oleh } \\
\text { seseorang atas suatu tempat tujuan (destination). }\end{array}$ \\
Assael (1984) & $\begin{array}{l}\text { Total persepsi atas suatu tempat yang terbentuk dengan memproses } \\
\text { informasi dari berbagai sumber dari waktu ke waktu. }\end{array}$ \\
Phelps (1986) & $\begin{array}{l}\text { Persepsi-persepsi atau kesan-kesan terhadap suatu tempat. } \\
\text { Gartner and Hunt (1987) } \\
\text { Kesan-kesan yang dimiliki seseorang terhadap tempat yang bukan } \\
\text { merupakan tempat tinggalnya. }\end{array}$ \\
\end{tabular}


Moutinho (1987) Sikap seseorang atas atribut-atribut suatu tempat tujuan berdasarkan pengetahuan dan perasaan yang dimilikinya.

Embacher and Buttle

Chon (1990)

Echtner and Ritchie

Dadgostar and Isotalo (1992)

Milman and Pizam (1995)

Mackay and Fesenmaier (1997)

Pritchard (1998)

Baloglu and McCleary (1999)

Coshall (2000)

Murphy et al. (2000)

Tapachai and Waryszak (2000)

Bigne et al. (2011)

Kim and Richardson (2003)
Gagasan dan konsepsi yang dimiliki oleh individu atau sekelompok orang atas daerah tujuan yang sedang dipelajari.

Hasil interaksi keyakinan, gagasan, perasaan, harapan, dan kesan yang dimiliki oleh seseorang tentang suatu daerah tujuan.

Persepsi atribut daerah tujuan secara terpisah dan kesan yang dibuat daerah tujuan secara terpadu.

Kesan dan sikap secara keseluruhan yang didapat oleh seseorang atas sebuah tempat.

Visual atau kesan mental atas suatu tempat, produk, atau pengalaman yang dimiliki oleh publik.

Gabungan berbagai produk (atraksi) dan atribut yang terjalin menjadi suatu kesan keseluruhan.

Suatu visual atau kesan mental atas tempat tertentu.

Representasi mental dari pengetahuan, perasaan, dan kesan secara umum, yang dimiliki seseorang atas suatu daerah tujuan.

Persepsi individu terhadap karakteristik daerah tujuan.

Penjumlahan (sum) asosiasi dan kepingan informasi terkait dengan daerah tujuan, dimana didalamnya termasuk beragam komponen tempat tujuan dan persepsi personal.

Persepsi atau kesan yang dimiliki oleh wisatawan terhadap daerah tujuan sehubungan dengan manfaat yang diharapkan atau nilai konsumsi (consumption values).

Interpretasi subyektif wisatawan atas kenyataan.

Keseluruhan kesan, keyakinan, gagasan, harapan, dan perasaan terhadap sebuah tempat yang terakumulasi dari waktu ke waktu.

Sumber: Martın and del Bosque (2008)

Dari berbagai definisi citra destinasi pada Tabel 2 dapat disimpulkan bahwa citra destinasi memiliki multidimensi yaitu:

1. Dimensi kognitif yaitu pengetahuan, konsepsi, dan interpretasi atas suatu tempat spesifik tertentu. Citra destinasi wisata kognitif adalah pengetahuan dan pemikiran seseorang tentang suatu obyek (Agapito et al., 2013). Dengan pendekatan kognitif maka citra destinasi wisata dievaluasi melalui atribut sumber daya (resources) dan atraksi yang dimiliki oleh suatu tempat wisata yang memotivasi seseorang untuk berkunjung ke tempat tersebut (Lopes, 2011).

2. Dimensi afektif yaitu kesan, prasangka, imajinasi, pemikiran-pemikiranemosional, keyakinan, persepsi, harapan yang dimiliki seseorang atas suatu tempat spesifik tertentu. Citra destinasi wisata afektif adalah perasaan yang dimiliki oleh seseorang tentang suatu obyek (Agapito et al., 2013). Pendekatan afektif merujuk kepada perasaan dan emosi yang dibangkitkan oleh tempat tujuan wisata tersebut (Isa dan Ramli, 2014).

3. Dimensi konatif yaitu gagasan dan sikap seseorang atas suatu tempat spesifik tertentu. Citra destinasi wisata konatif adalah bagaimana seseorang menggunakan informasi yang dimilikinya dalam mengambil suatu tindakan (Agapito et al., 2013). Tindakan yang diambil oleh respondent diukur dengan menggunakan niat perilaku seperti "keinginan untuk melakukan kunjungan (ulang), dan 
kesediaan untuk merekomendasikan kepada orang lain" (Lee dan Xie, 2011; Byon dan Zhang, 2010).

Dan dimensi-dimensi dari citra destinasi ini yaitu dimensi kognitif, dimensi afektif, dan dimensi konatif ini membentuk suatu model hiearki pembentukan citra destinasi (Agapito et al., 2013; Tasci et al., 2007).

\section{METODE PENELITIAN}

Metodologi yang digunakan dalam penelitian ini adalah metodologi penelitian kuantitatif. Penelitian kuantitatif adalah penelitian yang menghasilkan informasiinformasi statistik melalui survey penelitian (Dawson, 2007). Penelitian Pengembangan instrumen dilakukan dengan melakukan review literatur. Faktor-faktor citra destinasi yang dimasukkan dalam penelitian ini adalah faktor-faktor yang spesifik terhadap daerah tujuan wisata (Byon dan Zhang, 2010). Instrumen akan dikembangkan dengan mengadopsi penelitian-penelitian sebelumnya, tetapi tetap dengan mempertimbangkan relevansinya. Metode pengumpulan data yang digunakan dalam penelitian ini adalah melalui penyebaran kuesioner. Kuesioner disebarkan melalui jaringan internet. Subyek penelitian adalah mereka yang bukan penduduk DKI Jakarta, dan berusia minimal 17 tahun. Penentuan sampel menggunakan metode random sampling. Model penelitian dapat dilihat seperti pada Gambar 3 berikut:

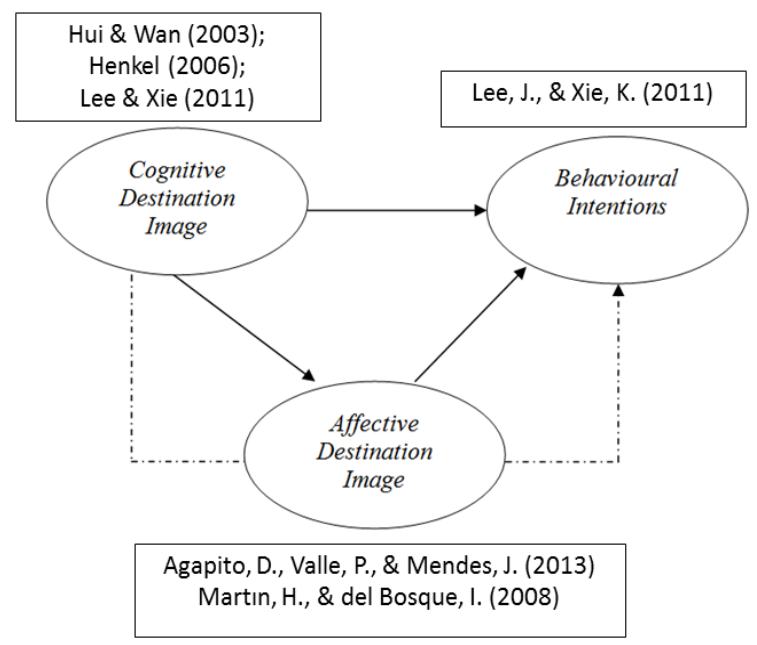

\section{Gambar 3. Model Penelitian}

Sumber: Agapito et al. (2013)

Analisa data dilakukan dengan menggunakan software SmartPLS. Tahapan teknik analis data yang dilakukan dalam penelitian ini adalah:

- Uji Konvergen Validitas, yaitu untuk menguji apakah alat ukur yang digunakan memiliki korelasi yang tinggi dengan alat ukur lain yang mengukur atribut yang sama. Uji validitas konvergen dilakukan dengan cara melakukan uji loading factors dan uji nilai Average Variance Extracted (AVE).

- Uji Validitas Diskriminan, yaitu untuk menguji apakah alat ukur yang digunakan memiliki korelasi yang rendah dengan alat ukur lain yang mengukur atribut yang berbeda. Uji validitas diskriminan dilakukan dengan cara uji nilai cross-loading factors.

- Uji Reliabilitas dilakukan dengan cara uji Cronbach Alpha.

- Analisa Inner Model (structural model) yaitu dengan melakukan uji nilai $\mathrm{T}$ statistik (uji siginifikansi) dan uji determinasi dengan nilai $\mathrm{R}^{2}$. 


\section{HASIL DAN PEMBAHASAN}

Jumlah responden yang berpartisipasi dalam penelitian ini adalah sebanyak 149 responden. Responden pria dan wanita hampir berimbang yaitu wanita 75 responden, dan pria 74 responden. Dilihat dari usia responden, 141 responden atau 95\% berusia 17-27 tahun, sedang sisanya 8 responden atau 5\% berusia 28-49 tahun. Berdasarkan tingkat pendidikan, 131 responden memiliki pendidikan terakhir sampai dengan SMA sederajat, 12 responden memiliki pendidikan S1, 5 responden memiliki pendidikan S2, dan 1 responden memiliki pendidikan S3.

Uji validitas dilakukan terhadap validitas konvergen dan validitas diskriminan. Uji Konvergen Validitas dilakukan dengan cara menguji nilai factor loadings dan nilai Average Variance Extracted (AVE). Sebagai rules of thumb, Hair et al. (2014) menyarankan standardized loading estimate dan AVE memiliki nilai 0.5 atau lebih tinggi agar mempunyai validitas konvergen yang cukup baik. Indikator yang memiliki nilai factor loadings kurang dari 0.5 harus dihilangkan dari analisa. Berikut adalah nilai standardized loading estimate dan nilai AVE setelah menghilangkan indikator yang mempunyai nilai factor loadings kurang dari 0.5 .
Tabel 4. Nilai Factor Loading

\begin{tabular}{|c|c|c|c|}
\hline & Afektif & Kognitif & Konatif \\
\hline A1 & 1.120928 & & \\
\hline$A 2$ & 1.113906 & & \\
\hline $\mathrm{A} 3$ & 0.972571 & & \\
\hline B1 & & & 0.902517 \\
\hline B2 & & & 0.993300 \\
\hline B3 & & & 0.997534 \\
\hline B4 & & & 0.961702 \\
\hline B5 & & & 0.833277 \\
\hline $\mathrm{CB} 1$ & & 0.651182 & \\
\hline CB2 & & 0.807989 & \\
\hline $\mathrm{CB} 3$ & & 0.772684 & \\
\hline CBU1 & & 0.928595 & \\
\hline CBU2 & & 0.893903 & \\
\hline CBU3 & & 0.842795 & \\
\hline CI1 & & 0.575916 & \\
\hline $\mathrm{CI} 2$ & & 0.603922 & \\
\hline CK1 & & 0.746263 & \\
\hline CK2 & & 0.739137 & \\
\hline CK3 & & 0.745982 & \\
\hline $\mathrm{CP} 1$ & & 0.690421 & \\
\hline $\mathrm{CP} 2$ & & 0.689291 & \\
\hline $\mathrm{CP} 3$ & & 0.691545 & \\
\hline CPL1 & & 0.665541 & \\
\hline CPL2 & & 0.657768 & \\
\hline CPL3 & & 0.602594 & \\
\hline CPL4 & & 0.684015 & \\
\hline CR1 & & 0.815575 & \\
\hline CR2 & & 0.937234 & \\
\hline CR3 & & 0.856842 & \\
\hline CS1 & & 1.006210 & \\
\hline CS2 & & 0.976305 & \\
\hline CS3 & & 0.909650 & \\
\hline
\end{tabular}

Sumber : data diolah 
Tabel 5. Nilai Average Variance Extracted (AVE)

\section{AVE}

\begin{tabular}{|c|c|}
\hline & AVE \\
\hline Afektif & 0.830242 \\
\hline Kognitif & 0.546300 \\
\hline Konatif & 0.736674 \\
\hline
\end{tabular}

Uji Validitas Diskriminan dilakukan dengan cara uji nilai cross-loading factors. Suatu indikator dikatakan memenuhi uji validitas diskriminan jika indikator memiliki nilai cross-loading relatif lebih besar dikolom variabel terkait, dibandingkan dikolom variabel lainnya. Berikut adalah gambar nilai cross-loading yang dimiliki oleh masingmasing indikator.
Tabel 6. Nilai Cross-Loading Factors Cross Loadings

\begin{tabular}{|c|c|c|c|}
\hline & Afektif & Kognitif & Konatif \\
\hline A1 & 0.915955 & 0.742491 & 0.789219 \\
\hline A2 & 0.936486 & 0.753258 & 0.807052 \\
\hline A3 & 0.880197 & 0.716671 & 0.771468 \\
\hline B1 & 0.830819 & 0.719462 & 0.873156 \\
\hline B2 & 0.759302 & 0.708721 & 0.879263 \\
\hline B3 & 0.798009 & 0.723032 & 0.905614 \\
\hline B4 & 0.709919 & 0.685144 & 0.845006 \\
\hline B5 & 0.586533 & 0.526978 & 0.783384 \\
\hline CB1 & 0.461001 & 0.535042 & 0.386075 \\
\hline CB2 & 0.617784 & 0.646195 & 0.497207 \\
\hline CB3 & 0.571840 & 0.624883 & 0.488410 \\
\hline CBU1 & 0.693844 & 0.822978 & 0.721527 \\
\hline CBU2 & 0.693052 & 0.838365 & 0.669763 \\
\hline СвUз & 0.666580 & 0.821164 & 0.650070 \\
\hline CI1 & 0.565068 & 0.663128 & 0.543490 \\
\hline $\mathrm{CI} 2$ & 0.620166 & 0.635456 & 0.533737 \\
\hline CK1 & 0.580311 & 0.653640 & 0.505408 \\
\hline CK2 & 0.567185 & 0.674393 & 0.567045 \\
\hline сK3 & 0.613435 & 0.698774 & 0.572544 \\
\hline CP1 & 0.533354 & 0.769808 & 0.552919 \\
\hline $\mathrm{CP2}$ & 0.539705 & 0.749573 & 0.566348 \\
\hline CP3 & 0.535855 & 0.754255 & 0.592757 \\
\hline CPL1 & 0.584905 & 0.757974 & 0.596648 \\
\hline CPL2 & 0.594579 & 0.756706 & 0.597649 \\
\hline CPL3 & 0.541289 & 0.757303 & 0.597064 \\
\hline CPL4 & 0.555570 & 0.702513 & 0.545095 \\
\hline CR1 & 0.615896 & 0.719281 & 0.607866 \\
\hline CR2 & 0.647316 & 0.805779 & 0.627781 \\
\hline CR3 & 0.652483 & 0.785796 & 0.640378 \\
\hline CS1 & 0.639230 & 0.823877 & 0.618534 \\
\hline $\operatorname{cs} 2$ & 0.613239 & 0.827107 & 0.618296 \\
\hline $\operatorname{cs} 3$ & 0.580632 & 0.814879 & 0.608417 \\
\hline
\end{tabular}

Sumber: data diolah 
Dari gambar diatas dapat dilihat bahwa indikator memiliki nilai cross-loading relatif paling besar sesuai dengan variabelnya. Dengan demikian dapat disimpulkan bahwa instrumen yang digunakan dalam penelitian ini telah memenuhi syarat uji validitas diskriminan.

Uji reabilitas dilakukan dengan melakukan uji Cronbachs Alpha. Hair et al. (2014) menyarankan agar instrumen memiliki nilai Cronbachs Alpha 0.7 atau lebih tinggi untuk dapat memenuhi syarat reabilitas. Berikut adalah nilai Cronbach's Alpha yang dimiliki:

\section{Tabel 7. Nilai Cronbachs Alpha}

\section{Cronbachs Alpha}

\begin{tabular}{|c|c|}
\hline & Cronbachs Alpha \\
\hline Afektif & 0.897399 \\
\hline Kognitif & 0.963040 \\
\hline Konatif & 0.910364 \\
\hline
\end{tabular}

Sumber: data diolah

Karena Cronbachs Alpha memiliki nilai $>0.7$ maka dapat dinyatakan bahwa instrumen memenuhi syarat reability dan dapat dilakukan analisa lebih lanjut. Uji signifikansi dilakukan dengan uji nilai $\mathrm{T}$. Dengan tingkat signifikansi 5\% maka nilai absolut T-test adalah 1.96. Artinya jika nilai $\mathrm{T}>1.96$ maka konstruk dimaksud dikatakan memiliki pengaruh signifikan. Berikut adalah hasil uji nilai $\mathrm{T}$ :

Tabel 8. Nilai T Statistics

\begin{tabular}{|l|c|}
\hline & $\begin{array}{c}\text { T Statistics } \\
(\text { IO/STERR I) }\end{array}$ \\
\hline Afektif $\rightarrow$ Konatif & 7.919664 \\
\hline Kognitif $\rightarrow$ Afektif & 17.201314 \\
\hline Kognitif $\rightarrow$ Konatif & 3.117347 \\
\hline
\end{tabular}

Sumber : data diolah

berdasarkan nilai $\mathrm{T}$ tersebut diatas dapat disimpulkan:

- Kognitif memiliki pengaruh signifikan terhadap Afektif (nilai T > 1.96);
- Kognitif memiliki pengaruh signifikan terhadap Konatif (nilai T > 1.96);

- Kognitif bersama-sama Afektif memiliki pengaruh signifikan terhadap Konatif (nilai $\mathrm{T}>1.96$ ).

Uji determinasi dilakukan untuk menjelaskan seberapa besar pengaruh suatu variabel terhadap variabel lainnya. Uji determinasi dilakukan dengan cara melihat nilai R-Square. Berikut adalah nilai $\mathrm{R}$ Square yang dimiliki oleh model:

Tabel 9. Nilai R Square

\begin{tabular}{|c|c|}
\hline & R Square \\
\hline Afektif & 0.655374 \\
\hline Kognitif & \\
\hline Konatif & 0.773379 \\
\hline
\end{tabular}

Sumber : data diolah

dari nilai R2 diatas dapat disimpulkan bahwa variabel Kognitif mempengaruhi variabel Afektif sebesar $65 \%$, dan variabel Kognitif secara bersama-sama dengan variabel Afektif mempengaruhi variabel Konatif sebesar $77 \%$.

Uji mediasi dilakukan untuk mengetahui apakah variabel mediator (Afektif) memediasi pengaruh variabel predictor (Kognitif) terhadap variabel criterion (Konatif). Hair et all (2014) memberikan langkah-langkah untuk uji mediasi sebagai berikut:

1. Lakukan uji dengan model variabel predictor (Kognitif) terhadap criterion (Konatif);

2. Lakukan uji kembali dengan memasukkan variabel mediator (Afektif) ke dalam model;

3. Lihat signifikansi dan nilai signifikansi sebelum dan sesudah variabel moderator dimasukkan dalam model:

a. Jika hubungan antara Kognitif dan Konatif, sebelum dan sesudah variabel mediator dimasukkan dalam model tetap signifikan dan tidak berubah maka dapat disimpulkan TIDAK TERDAPAT MEDIASI; 
b. Jika hubungan antara Kognitif dan Konatif, sebelum dan sesudah variabel mediator dimasukkan dalam model tetap signifikan tetapi nilainya berkurang maka dapat disimpulkan TERDAPAT MEDIASI SEBAGIAN;

c. Jika hubungan antara Kognitif dan Konatif, sesudah variabel mediator dimasukkan dalam model menjadi TIDAK signifikan maka dapat disimpulkan TERDAPAT MEDIASI PENUH.

Jika langkah-langkah tersebut dilakukan maka berikut adalah nilai hubungan Kognitif dan Konatif sebelum dan sesudah variabel mediator dimasukkan ke dalam model:

Tabel 10. Nilai T Statistic Sebelum Memasukkan Variabel Mediasi

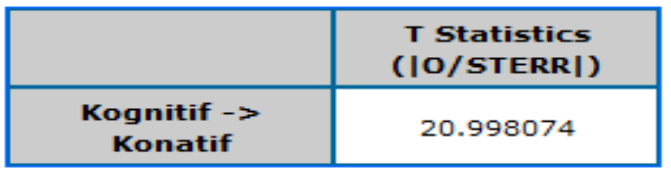

Sumber : data diolah

Tabel 11. Nilai T Statistic Setelah Memasukkan Variabel Mediasi

\begin{tabular}{|l|c|}
\hline & $\begin{array}{c}\text { T Statistics } \\
(\text { IO/STERRI) }\end{array}$ \\
\hline Afektif $->$ Konatif & 7.919664 \\
\hline Kognitif $->$ Afektif & 17.201314 \\
\hline Kognitif $->$ Konatif & 3.117347 \\
\hline
\end{tabular}

Sumber : data diolah

berdasarkan data diatas diketahui bahwa sebelum variabel mediator dimasukkan dalam model maka nilai $\mathrm{T}$ adalah 20.99 (signifikan), dan setelah variabel mediator dimasukkan dalam model maka nilai $\mathrm{T}$ adalah 3.11 (signifikan). Dengan demikian dapat disimpulkan bahwa variabel Afektif memediasi sebagian pengaruh variabel Kognitif terhadap variabel Konatif.

\section{SIMPULAN DAN SARAN}

\section{Simpulan}

Berdasarkan hasil penelitian diatas maka dapat diambil kesimpulan:

1) Informasi dan fakta (kognitif) yang dimiliki oleh seseorang tentang suatu tempat tujuan wisata tertentu akan mempengaruhi tindakan (konatif/behavioral) yang akan dilakukan oleh orang tersebut terhadap tempat wisata bersangkutan.

2) Informasi dan fakta yang dimiliki oleh seseorang (kognitif) tentang suatu tempat tujuan wisata tertentu akan mempengaruhi perasaan (afektif) yang dimiliki oleh orang tersebut terhadap tempat wisata bersangkutan.

3) Perasaan yang dimiliki oleh seseorang (afektif) tentang suatu tempat tujuan wisata tertentu akan mempengaruhi tindakan (konatif/behavioral) yang akan dilakukan oleh orang tersebut terhadap tempat wisata bersangkutan.

4) Perasaan (afektif) MEMEDIASI pengaruh informasi dan fakta (kognitif) yang dimiliki oleh seseorang tentang suatu tempat tujuan wisata atas tindakan (konatif/behavioral) yang akan dilakukan oleh orang tersebut terhadap tempat wisata bersangkutan.

Implikasi bagi pemasar wisata adalah menyadari bahwa keputusan untuk melakukan kunjungan ke suatu tempat wisata bukanlah suatu proses instan tetapi adalah proses persepsi dan kognitif calon wisatawan terhadap berbagai sumber informasi. Keputusan tentang tempat wisata yang akan dikunjungi adalah hasil dari perasaan yang dimiliki seseorang (afektif) atas tenpat wisata tersebut, dan perasaaan yang dimiliki seseorang terhadap suatu tempat wisata adalah proses intrepretasi calon wisatawan terhadap berbagai informasi, baik informasi yang memang ditujukan menjadi informasi wisata maupun informasi umum yang didapat melalui saluran komunikasi publik.

Pemasar wisata harus mulai memperhatikan informasi-informasi tentang tempat wisata yang akan dipasarkan. Jika 
selama ini pemasar wisata -khususnya Kementerian Pariwisata dan Dinas Pariwisata Daerah- hanya berkonsentrasi dalam penyebaran informasi yang memang ditujukan sebagai informasi wisata (akan menjadi induced destination image bagi wisatawan) maka ada baiknya Kementerian Pariwisata dan Dinas Pariwisata Daerah juga mengintervensi informasi-informasi yang terdapat dalam berbagai saluran berita umum (media, sosial media, dan lain-lain) yang nantinya akan membentuk organic image bagi wisatawan.

\section{Saran}

Berdasarkan simpulan penelitian diatas, maka peneliti memberikan beberapa masukkan saran antara lain:

1) Pihak-pihak yang bertanggungjawab dalam mempromosikan pariwisata khususnya Kementerian Pariwisata dan Dinas Pariwisata Daerah tidak meremehkan dampak pemberitaanpemberitaan yang dilakukan oleh media atas peristiwa yang terjadi di suatu daerah tertentu apalagi yang merupakan daerah tujuan wisata. Hal ini dikarenakan informasi-informasi dari pemberitaan tersebut dapat mempengaruhi perasaan dan tindakan seseorang untuk melakukan kunjungan wisata ke tempat tersebut. Pemerintah harus dapat meminimalisir dampak pemberitaan jika terkait kepada hal-hal negatif seperti aksi terorisme atau aksi kejahatan yang terjadi didaerah tersebut, ataupun memaksimalkan dampak pemberitaan jika terkait kepada hal-hal positif daerah tersebut.

2) Pihak-pihak yang bertanggungjawab dalam mempromosikan pariwisata khususnya Kementerian Pariwisata dan Dinas Pariwisata Daerah secara kreatif menyebarkan informasi-informasi positif kepada khalayak ramai tentang suatu daerah tujuan wisata. Hal ini misalnya dengan mengundang media untuk mengexplore atraksi dan keindahan suatu daerah tujuan wisata. Tulisan-tulisan media -apalagi media yang kredibleakan menjadi informasi kognitif dan pada akhirnya akan mempengaruhi perasaan dan tindakan orang untuk berwisata ke daerah tersebut.

3) Pihak-pihak yang bertanggungjawab dalam mempromosikan pariwisata khususnya Kementerian Pariwisata dan Dinas Pariwisata Daerah secara kreatif menyebarkan informasi-informasi positif tentang suatu tempat wisata khususnya kepada generasi muda -yang akan menjadi wisatawan masa depan-. Hal ini dapat dilakukan misalnya dengan menyisipkan informasi tersebut dalam materi-materi sekolah yang diakses oleh pelajar. Informasi-informasi kognitif yang positif dan menyenangkan atas suatu daerah tujuan wisata akan memiliki signifikan dalam mempengaruhi perasaan dan tindakan generasi uda ini ketika mereka sudah memiliki kemampuan untuk mennetukan daerah wisata yang akan mereka kunjungi.

4) Memfasilitasi penduduk lokal ditempat wisata untuk juga dapat menyebarkan informasi-informasi positif serta atraksiatraksi menarik didaerahnya melalui komunikasi-komunikasi yang dilakukan. Pemasaran wisata yang selaras dengan perspektif penduduk lokal akan memiliki tingkat keberhasilan yang lebih tinggi dikarenakan penduduk lokal akan mendukung untuk memberikan pengalaman wisata seperti informasi yang didapatkan oleh wisatawan (Budi, 2016).

\section{DAFTAR PUSTAKA}

Agapito, D., Valle, P., \& Mendes, J. (2013). The cognitive-affective-conative model of destination image. Journal of Travel \& Tourism Marketing, h. 471481.

Akroush, M., Jraisat, L., Kurdieh, D., AlFaouri, R., \& Qatu, L. (2016). Tourism 
service quality and destination loyalty - the mediating role of destination image from international tourists' perspectives. Tourism Review, preprinted version.

Al-Kwifi, O. S. (2015). The impact of destination images on tourists' decision making. Journal of Hospitality and Tourism Technology, h. 174-194.

Allameh, S., Pool, J., Reza, A., \& Asadi, S. (2015). Factors influencing sport tourists' revisit intentions. Asia Pacific Journal of Marketing and Logistics, h. 191-207.

Budi (2016). Strategi Pemasaran Jakarta Sebagai Destinasi Wisata Yang Selaras Dengan Persepsi Penduduk Lokal, Jurnal Ilmiah Hospitality Management, h. 85-92

Byon, K., \& Zhang, J. (2010). Development of a scale measuring destination image. Marketing Intelligence \& Planning, $\mathrm{h}$. 508-532.

Chen, C., \& Tsai, D. (2007). How destination image and evaluative factors affect behavioral intentions? Tourism Management, h. 1115-1122.

Dinas Pariwisata Dan Kebudayaan Provinsi DKI Jakarta. (2013). Rencana Strategi Dinas Pariwisata Dan Kebudayaan Provinsi Dki Jakarta Tahun 20132017. Jakarta: Dinas Pariwisata Dan Kebudayaan Provinsi DKI Jakarta.

Echtner, C. \& Ritchie, J (1991) The measuring and measurement of destination image. The Journal of Tourism Studies, p.2-12.

Echtner, C. \& Ritchie, J. (2003). The Meaning and Measurement of
Destination Image. The Journal of Tourism Studies, h. 38-48.

Greaves, N., \& Skinner, H. (2010). The importance of destination image analysis to UK rural tourism. Marketing Intelligence \& Planning, $\mathrm{h}$. 486-507.

Henkel, R., Henkel, P., Agrusa, W., Agrusa, J., \& Tanner, J. (2006). Thailand as a Tourist Destination: Perceptions of International Visitors and Thai Residents. Asia Pacificfournal of Tourism Research, h. 269-287.

Hui, T. K. and Wan, T. W. D. (2003), Singapore's image as a tourist destination. International Journal of Tourism Research, h. 305-313

Isa, S., \& Ramli, L. (2014). Factors influencing tourist visitation in marine tourism: lessons learned from FRI Aquarium Penang,Malaysia. International Journal of Culture, Tourism and Hospitality Research, h. 103-117.

Kong, W., Cros, H., \& Ong, C. (2015). Tourism destination image development: a lesson from Macau. International Journal of Tourism Cities, h. 299-316.

Lee, J., \& Xie, K. (2011). Cognitive Destination Image, Destination Personality and Behavioral Intentions: An Integrated Perspective of Destination Branding. 16th Graduate Students Research Conference (pp. 112). Houston: University of Massachusetts Amherst Community.

Lopes, S. (2011). Destination image: Origins, Developments and Implications. Journal of Tourism and Cultural Heritage, h. 305-315. 
Martın, H., \& del Bosque, I. (2008). Exploring the cognitive-affective nature of destination image and the role of psychological factors in its formation. Tourism Management, 263277.

Tasci, A., Gartner, W., \& Cavusgil, S. (2007). Conceptualization and Operationalization of Destination Image. Journal of Hospitality \& Tourism Research, p .194-223.

World Travel \& Tourism Council. (2015a). Travel \& Tourism Economic Impact 2015 - Indonesia. 2015: World Travel $\&$ Tourism Council.

World Travel \& Tourism Council. (2015b). Travel \& Tourism Economic Impact 2015 - World. London: World Travel $\&$ Tourism Council.

http://industri.bisnis.com/read/20170218/12/6 29896/kunjungan-wisman-2016-lebihi-target12-juta-orang, diakses 20 Januari 2017.

http://www.koran-jakarta.com/pariwisatakunci-penggerak-ekonomi-global/, diakses 20 Januari 2017. 